\title{
The relationship between demographic and anthropometric characteristics and diabetic complications and number of hospitalizations in hospitalized diabetic patients
}

Yusuf Kayar ${ }^{1}$, Mehmet Agin²

${ }^{1}$ Department of Internal Medicine, Faculty of Medicine, Bezmialem Vakıf University, Istanbul, Turkey

${ }^{2}$ Department of Pediatrics, Van Education and Research Hospital, Van, Turkey

Submitted: 18 September 2018

Accepted: 7 January 2019

Arch Med Sci Civil Dis 2019; 4: e7-e15

DOI: https://doi.org/10.5114/amscd.2019.81668

Copyright (c) 2019 Termedia \& Banach

\begin{abstract}
Introduction: Diabetes mellitus is the most common endocrine disease in the world. A total of 371 million people with diabetes lived in the world in 2012, 4.8 million people lost their lives due to diabetes, and 612-1099 billion dollars are spent on diabetic patients each year. The aim of our study was to investigate the relationship between the number of hospitalized patients, the demographic and anthropometric characteristics, and diabetic complications.
\end{abstract}

Material and methods: Five hundred patients hospitalized with DM diagnosis were included in this study. Patients were divided into three groups according to the number of hospitalizations. The relationship between the number of hospitalizations and risk factors was examined. Parameters were analyzed using linear regression, $\chi^{2}$ test and independent $t$-test.

Results: When the number of hospitalizations was classified, the groups were formed as the patients who were hospitalized once, twice, or three times or more, respectively: 351 (70.2\%), 86 (17.2\%), and 63 (12.6\%). In our study, it was found that patients with three times or more hospitalizations had worse glycemic control, duration of diabetes, and rate of taking insulin treatment, which was found to be significantly high $(p<0.05)$, the number of non-smokers was significantly low $(p<0.05)$, the quitting rate was significantly high $(p<0.05)$, nephropathy, retinopathy, and cerebrovascular events and cardiovascular diseases were significantly high $(p<0.05)$ compared to one and two hospitalizations.

Conclusions: In our study, it was found that glycemic control and diabetic complications were important determinants in the control of diabetes-related hospitalizations; and well-controlled diabetes was found to reduce the number of hospital admissions of patients with diabetes in Turkey. There are no financial data; however, in this context, it can be envisaged that it will have a lowering effect on the cost per patient.

Key words: diabetes mellitus, hospitalization, diabetic complications.

\section{Introduction}

Diabetes mellitus (DM), in which the organism cannot make use of carbohydrates, fats and proteins due to insulin deficiency or defects in

\author{
Corresponding author: \\ Dr. Mehmet Agin \\ Department \\ of Pediatrics \\ Van Education \\ and Research Hospital \\ Van, Turkey \\ Phone: +90 5068011083 \\ E-mail: drmehmet47@ \\ yahoo.com
}


insulin, and that requires continuous medical care, is a chronic metabolic disease and the most frequently seen endocrine disease in the world [1]. In 2012, there were 371 million people with diabetes worldwide, 4.8 million people lost their lives due to diabetes, and about $\$ 471$ million were spent on healthcare for diabetic patients. It is estimated that in 2030 there will be 552 million diabetics [2]. In 2014, it was estimated that the average health expenditure per diabetic individual varied between $\$ 1,583$ and $\$ 2,842$ worldwide. Estimated annual global health expenditures on diabetes vary from $\$ 612$ billion to $\$ 1099$ billion [3]. In Turkey, the DM prevalence was determined to be $7.7 \%$ in the first Turkish Diabetes, Hypertension, Obesity and Endocrinology Diseases Prevalence (TURDEP) study conducted in 1998-1999, and it was seen to reach $13.7 \%$ in the TURDEP II study conducted in 2010 [4, 5]. It is also observed that the increase in frequency of complications is a serious burden for health and the economy with the increasing life time as a result of recent rapidly developing DM treatments $[6,7]$.

Diabetes is known to cause very serious complications such as coronary artery disease, nephropathy and retinopathy [6-8]. The American Diabetes Association (ADA) recommends keeping the target glycated hemoglobin $\left(\mathrm{HbA}_{1 \mathrm{c}}\right)$ below $7 \%$ when a linear relationship between microvascular and macrovascular complications and $\mathrm{HbA}_{1 \mathrm{c}}$ is considered [9-11]. Good medical care and selfmanagement are needed to prevent acute complications and to reduce long-term complications [1]. The development of complications also markedly increases the cost to the country [12]. In previous studies, it was detected that there was a significant reduction in healthcare costs and hospitalization rates with provision of good glycemic control [12].

When DM patients were examined in terms of hospitalization indications, it was seen that the most important indications for hospitalization were ischemic heart disease, infections, blood glucose irregularity and electrolyte imbalance [12-14]. When the relationship between hospitalization and risk factors in diabetic patients was examined, it was found that the hospitalization rate was significantly higher in patients with poor glycemic control and high blood pressure [12, 14]. As a result, it is thought that there is a significant relation between the number of hospitalizations, various indications for hospitalization and some risk factors and glycemic control.

For this purpose, in our study, we performed an analysis of the relationship between 500 hospitalized diabetic patients' glycemic control, demographic anthropometric characteristics, diabetic complications and hospitalization rates.

\section{Material and methods}

This study included 500 patients who were hospitalized between January 1, 2017 and January 1, 2018 with the diagnosis of type 1 DM or type $2 \mathrm{DM}$ at the Endocrinology and Metabolic Diseases Clinic. The patients' data were documented in the one-year follow-up prospectively. Voluntary patients aged 17 years and over with type 1 DM or type 2 DM who signed a consent form for study were included in the study. Patients younger than 17 years, patients with type 1 DM or type 2 DM but who were hospitalized for reasons other than the specified indications, pregnant patients, and non-voluntary patients despite compliance with inclusion criteria were not included in the study. Demographic anthropometric characteristics, laboratory data, use of antidiabetic therapy (oral antidiabetic drug (OAD), insulin alone, OAD + insulin only), and presence of diabetic complications were documented in hospitalized patients.

\section{Clinical and laboratory measurements}

The diagnosis of DM was made according to the ADA criteria. Systolic and diastolic blood pressures were measured using an automatic blood pressure monitor with a suitable cuff size on the right arm after a rest period of 10 min. Patients with systolic/diastolic blood pressure $\geq 140 / 90 \mathrm{~mm} \mathrm{Hg}$ or using antihypertensive drugs were evaluated as hypertensive patients. Height $(\mathrm{m})$ and weight $(\mathrm{kg})$ measurements were performed to calculate the body mass index (BMI), which was calculated with the formula (weight)/(height $\times$ height). The patients were evaluated according to the BMI scores (normal weight with $\mathrm{BMI}<25 \mathrm{~kg} / \mathrm{m}^{2}$, overweight with $\mathrm{BMI}=25-29 \mathrm{~kg} / \mathrm{m}^{2}$, obese with $\mathrm{BMI} \geq 30 \mathrm{~kg} /$ $\mathrm{m}^{2}$ ). Good glycemic control was defined as having a $\mathrm{HbA}_{1 \mathrm{c}}$ level $<7 \%$, and poor glycemic control was defined as having a $\mathrm{HbA}_{1 \mathrm{c}}$ level $\geq 7 \%$. The criteria for diagnosis of dyslipidemia were determined as cholesterol level $\geq 200 \mathrm{mg} / \mathrm{dl}$, high-density lipoprotein $(\mathrm{HDL})<50 \mathrm{mg} / \mathrm{dl}$ (female), $\mathrm{HDL}<40 \mathrm{mg} / \mathrm{dl}$ (male), low-density lipoprotein $\mathrm{LDL} \geq 100 \mathrm{mg} / \mathrm{dl}$, triglyceride $\geq 150 \mathrm{mg} / \mathrm{dl}$. The patients with one or more of them, and patients with drug treatment despite normal values, were evaluated as dyslipidemic [11].

\section{Diabetic complications}

Retinopathy was investigated with ophthalmological examination made by an ophthalmologist in all cases. The test of protein and creatinine clearance in 24-hour urine and urinalyses were performed in terms of nephropathy. The glomerular filtration rate was calculated, and urinary ultrasonography was performed. The presence of 
neuropathy in patients was assessed by questioning complaints such as burning and tingling sensation, pain, stinging, etc. in the extremities. In the patients with arthralgia, arthropathy was investigated with arthrography and magnetic resonance imaging. The presence of cardiovascular diseases was investigated by performing echocardiography, coronary angiography and vascular ultrasonography in the necessary patients together with the examination and electrocardiogram by the cardiologist and cardiovascular surgeon. The presence of cerebrovascular diseases was documented by clinical questioning and neurological examination of the patients.

\section{Indications for hospitalization and number hospitalizations}

The reasons for hospitalization were documented. Ischemic heart disease, congestive heart failure, electrolyte imbalance, pneumonia, urinary system infection, hyperglycemia, hypoglycemia, retinopathy, nephropathy, neuropathy, diabetic foot infection, ketoacidosis and non-ketotic hyperosmolar coma were taken as reasons for hospitalization. The patients' durations of hospitalization were documented in the 1-year follow-up prospectively. In terms of the number of hospitalizations, patients were divided into three groups as one hospitalization, two hospitalizations, and three or more hospitalizations. The relationship between demographic and anthropometric characteristics, diabetic complications and number of hospitalizations was examined.

\section{Ethics statement}

All participants gave written permission to participate in the study. Ethics approval for conducting this study was taken from the Ethics Committee of the hospital (Istanbul, Turkey). All the procedures were in line with the ethical standards of our institution's human experiment committee and the Helsinki Declaration.

\section{Statistical analysis}

The SPSS 22.0 package program was used for statistical analysis of the data. The data were summarized as percentage and mean. The relationship between the duration of hospital stay and the patients' demographic and anthropometric characteristics was analyzed using linear regression, the independent $t$ test and the $\chi^{2}$ test. The relationship between diabetic complications and number of hospitalizations was analyzed using the independent $t$ test and the $\chi^{2}$ test. The results were evaluated with the hazard ratio and $95 \%$ confidence interval. A $p$-value of $<0.05$ was considered statistically significant in these analyses.

\section{Results}

A total of 500 patients aged 17 years and over who were hospitalized due to DM diagnosis were included in the study. Of the patients, 94 (18.8\%) were type $1 \mathrm{DM}$ and 406 (81.2\%) were type $2 \mathrm{DM}$. Of the patients, 188 (37.6\%) were male while 312 $(62.4 \%)$ were female. The mean age of the patients with the age range of $17-91$ years was 52.9 years. A total of $76 \%$ (380) of the patients were under 65 years of age, while $24 \%$ of the patients (120) were 65 years of age or older. The mean age at disease onset of the patients with the age range at disease onset of 4-79 years was 42.6 years. When the age at disease onset in the patients was analyzed, 32 (6.4\%) patients were within the ages of $1-17,437$ (87.4\%) patients were within the ages of $17-64$, and $31(6.2 \%)$ patients were 65 years or older. The treatments in the patients were divided into groups in the form of oral antidiabetics, insulin and combinations thereof. A total of $50(10 \%)$ of patients were taking only OAD, 170 (34\%) were taking only insulin, 279 (55.8\%) were taking insulin and OAD, and 1 (0.2\%) was taking exenatide. The BMI scores were calculated by measuring patients' height and weight.

According to the BMI scores, it was found that 80 (16\%) patients were normal, 120 (24\%) patients were overweight and $300(60 \%)$ patients were obese. When arterial blood pressures of the patients were measured in terms of hypertension presence, it was found that 193 (38.6\%) patients had no hypertension, and 307 (61.4\%) patients were hypertensive. When the patients were examined in terms of smoking, it was determined that 350 (70\%) did not smoke, 52 (10.4\%) had quit smoking and 98 (19.6\%) were still smoking. Patients were evaluated in terms of lipid profiles. In the patients whose total cholesterol levels were measured, total cholesterol level was below $200 \mathrm{mg} / \mathrm{dl}$ in 268 (53.6\%) patients, whereas total cholesterol level was $200 \mathrm{mg} / \mathrm{dl}$ and above in $232(46.4 \%)$ patients. The triglyceride levels were below $150 \mathrm{mg} / \mathrm{dl}$ in 232 (46.4\%) patients whereas the triglyceride levels were $150 \mathrm{mg} / \mathrm{dl}$ or above in 268 (53.6\%) patients. The LDL cholesterol level in 210 (42\%) patients was below $100 \mathrm{mg} / \mathrm{dl}$, whereas the LDL cholesterol level was $100 \mathrm{mg} /$ dl or above in 290 (58\%) patients. It was found that 282 (56.4\%) patients had low HDL cholesterol levels and 218 (43.6\%) patients had normal HDL cholesterol levels. When the disease durations of the patients were evaluated, it was found that the DM disease durations of 173 (34.6\%) patients were 7 years and below, and the DM disease durations of 327 (65.4\%) patients were longer than 7 years. The lowest $\mathrm{HbA}_{1 c}$ level was $6.2 \%$ while the highest $\mathrm{HbA}_{1 c}$ level was $20.6 \%$. The mean $\mathrm{HbA}_{1 c}$ level was found to be $10.7 \%$. When the $\mathrm{HbA}_{1 \mathrm{c}}$ lev- 
el $\geq 7 \%$ was considered as poor glycemic control, the number of patients with good glycemic control was 51 (10.2\%) while the number of patients with poor glycemic control was 449 (89.8\%). The hospitalization reasons of the patients were documented. A total of 401 (80.2\%) patients were hospitalized due to hyperglycemia, 34 (6.8\%) patients due to ketoacidosis, 25 (5\%) patients due to non-ketotic hyperosmolar coma, $23(4.6 \%)$ patients due to electrolyte imbalance, 22 (4.4\%) patients due to hypoglycemia, and 17 (3.4\%) patients due to retinopathy, $12(2.4 \%)$ patients due to urinary tract infection, 9 (1.8\%) patients due to hypertension, $7(1.4 \%)$ patients due to diabetic foot infection, 7 (1.4\%) patients due to nephropathy, 7 (1.4\%) patients due to ischemic heart disease, 5 (1\%) patients due to neuropathy, $4(0.8 \%)$ patients due to pneumonia, $2(0.4 \%)$ patients due to congestive heart failure. A total of 430 (86\%) of the patients who were hospitalized had one hospitalization diagnosis, and 70 (14\%) had two hospitalization diagnoses (Figure 1).

The hospitalization numbers of patients were maximum 11 , and minimum 1 . The mean number of hospitalizations was 1.57 in the patients. When the number of hospitalizations was divided into groups, it was found that 351 (70.2\%) of the patients were hospitalized once, $86(17.2 \%)$ of the patients were hospitalized twice, and 63 (12.6\%) of the patients were hospitalized three or more times. The relationship between the number of hospitalizations and demographic and anthropometric characteristics was evaluated. There was a significant relationship between the number of hospitalizations and poor glycemic control. The patients hospitalized three or more times were found to have worse glycemic control than those hospitalized once or twice. It was found that the duration of diabetes was significantly longer in patients hospitalized three or more times. It was determined that the rate of taking insulin treatment was significantly higher in those who were hospitalized three or more times. In patients hospitalized three or more times, it was found that the number of non-smokers was significantly lower, and the smoking cessation rate was significantly higher. There was no significant relationship between the number of hospitalizations and other parameters (Figure 2, Table I).

The relationship between the number of hospitalizations and complications was evaluated. Nephropathy, retinopathy, cerebrovascular events and cardiovascular diseases were found to be significantly higher in patients hospitalized three or more times. There was no significant relationship between neuropathy, amputation and the number of hospitalizations (Figure 3, Table II).

\section{Discussion}

In our study, the relationship between hospitalization numbers and diabetic complications in type- 1 and type-2 DM patients and the relationship between demographic-anthropometric characteristics, glycemic control and the hospitalization due to diabetes were investigated. Our study makes determinations on hospital admissions that are related to diabetes with a wide participation in Turkey. In assessment of hospitalization in diabetic patients, it was found that the high $\mathrm{HbA}_{1 c}$ levels increase the number hospitalizations, and there was

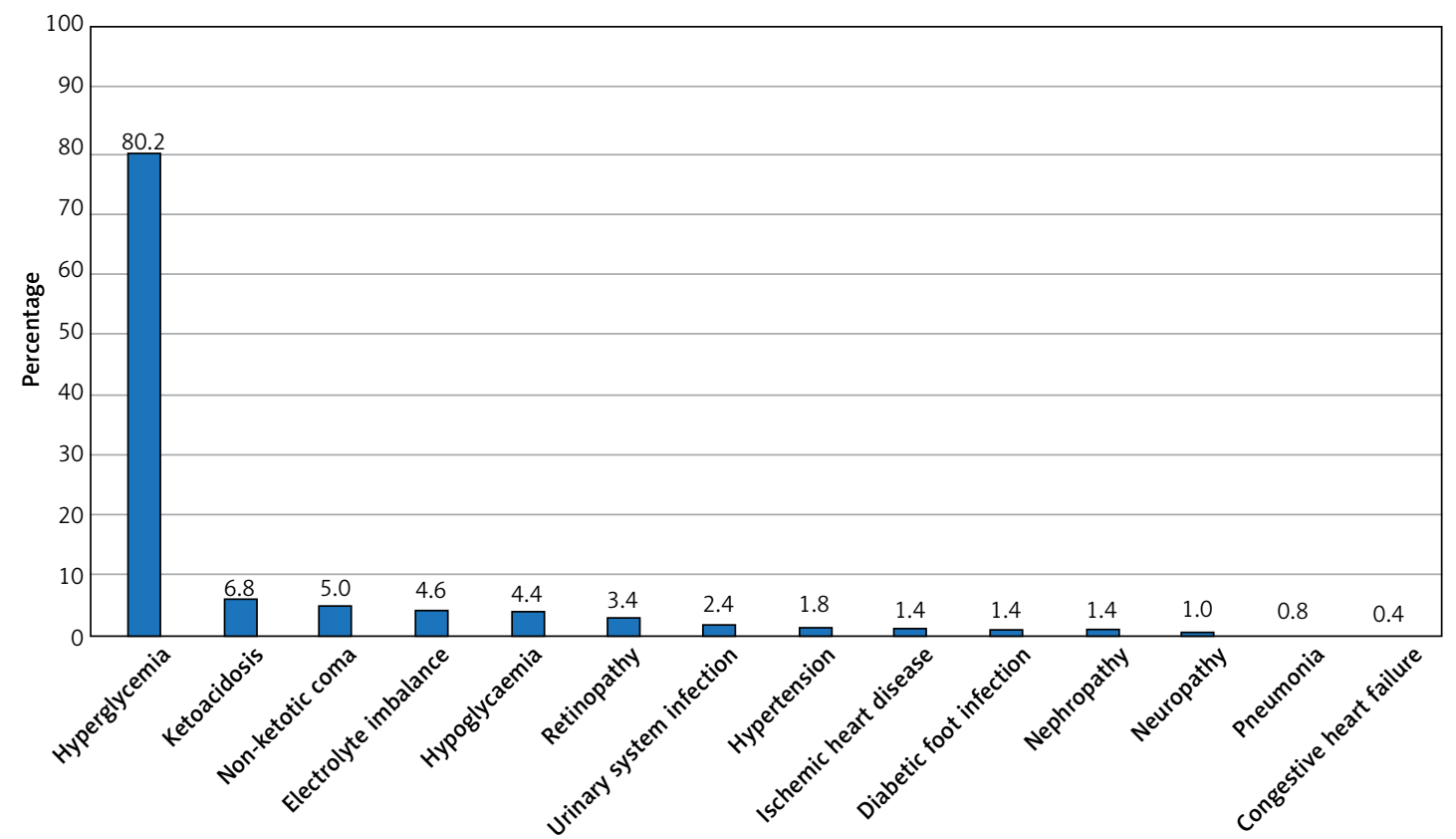

Figure 1. Distribution of patients according to the reasons for hospitalization 
A

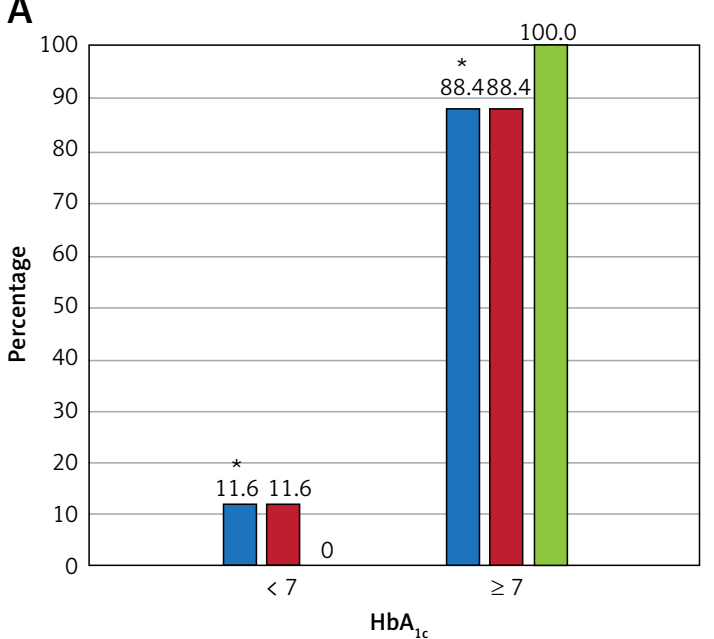

C

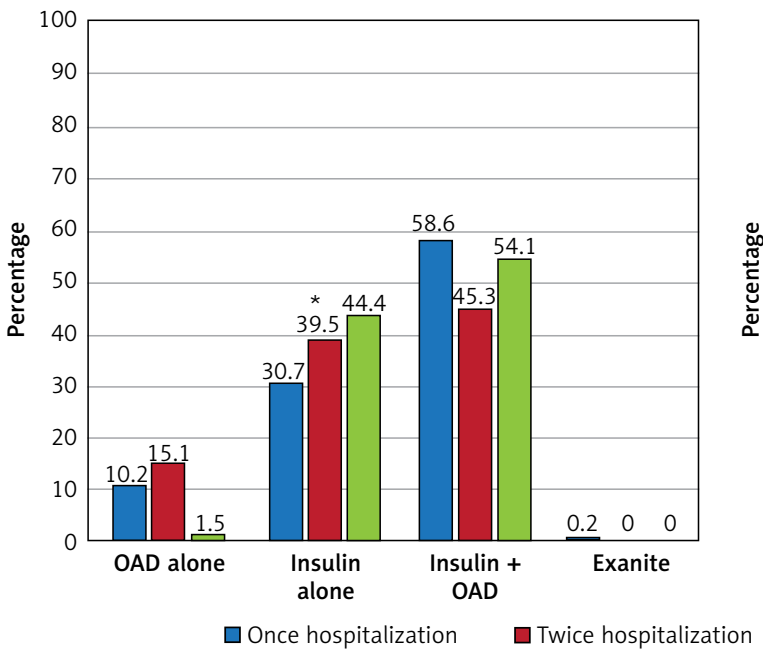

B

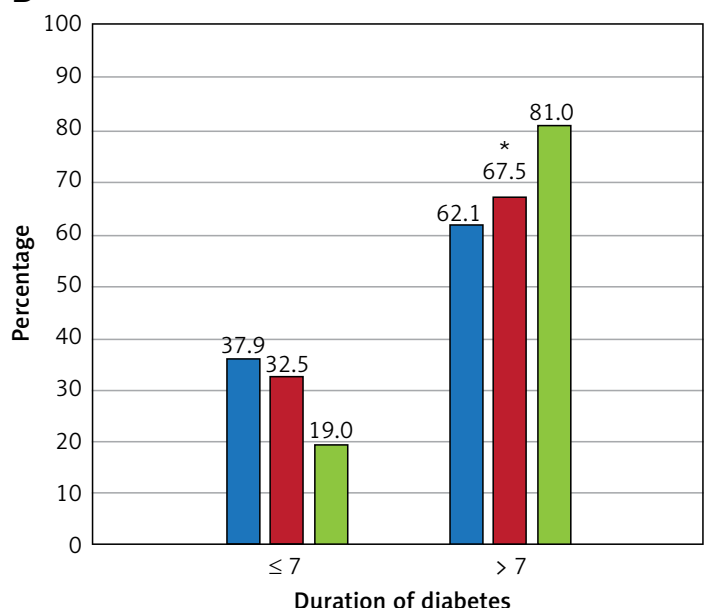

D

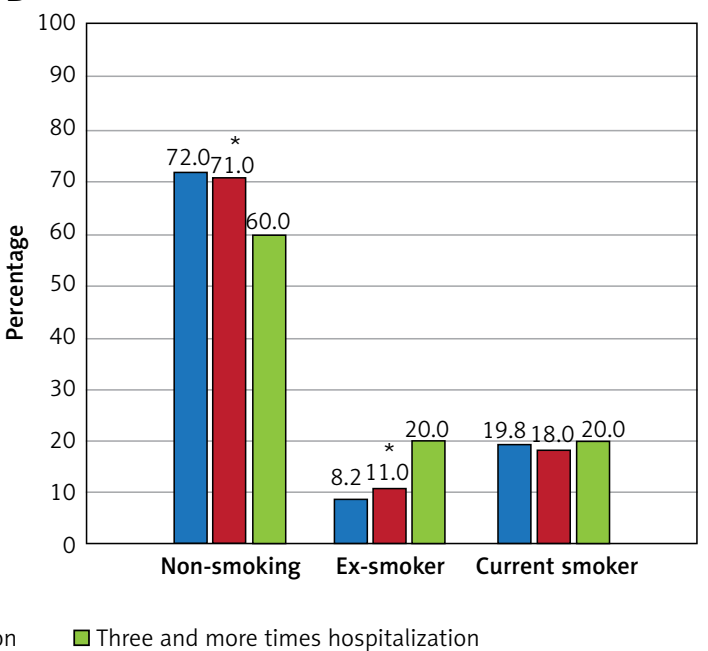

Figure 2. Relationship between number of hospitalizations and demographic and anthropometric data *Significant relationship.

a correlation between hospitalization number and diabetic complications. Our study showed that glycemic control was determinant for the control of diabetes-related hospitalizations, and good control of diabetes reduced the number of hospitalizations due to diabetes in Turkey. Since there are no cost data in this context, it is also anticipated that it will have a decreasing effect on the cost per patient.

To investigate the efficacy of glycosylated hemoglobin values on hospitalizations, the hospitalization rates for the year 2011 were compared with the data that were obtained at the end of a 4-year follow-up study conducted by Menzin et al. [8]. Menzin et al. [12] conducted a more extensive study in 2010 to assess diabetes-related hospitalizations. As a result of this study, it was found that there was a correlation between $\mathrm{HbA}_{1 \mathrm{c}}$ and hospitalization rates, in accordance with our study.

Gilmer et al. [15] conducted a study for Minnesota health planning in 2005 and found that a high level of $\mathrm{HbA}_{1 \mathrm{c}}$ increased the rates, duration and costs of hospitalization in all DM patient groups. However, in addition, it was demonstrated that diabetes-related hypertension, depression and cardiovascular disorders are also important determinants of the hospitalization duration. In 1999, Moss et al. [14] conducted a community-based study investigating the hospitalizations in DM patients and evaluating the demographic characteristics of patients in addition to $\mathrm{HbA}_{1 \mathrm{c}}$, and reported that $\mathrm{HbA}_{1 \mathrm{c}}$ levels and hypertension were determinants of hospitalization in $\mathrm{DM}$ patients who were diagnosed before the age of 30 and who were using insulin. Age, gender, BMI, smoking and alcohol consumption were not found to have an effect on hospitalization. In late-diagnosed diabetics (diagnosed after age 30), only $\mathrm{HbA}_{1 \mathrm{c}}$ levels were associated with hospitalization. Although the effect of $\mathrm{HbA}_{1 \mathrm{c}}$ on the number of hospitalizations in our study was similar, it was also found that the duration of diabetes and the 
Table I. Relationship between number of hospitalizations and demographic and anthropometric data

\begin{tabular}{|c|c|c|c|c|}
\hline \multirow[t]{2}{*}{ Parameter } & \multicolumn{3}{|c|}{ Number of hospitalizations } & \multirow[t]{2}{*}{$P$-value } \\
\hline & 1 & 2 & $\geq 3$ & \\
\hline Gender: & & & & NS $(0.7)$ \\
\hline Female & 220 (62.6\%) & $51(59.3 \%)$ & $41(65 \%)$ & \\
\hline Male & 131 (37.3\%) & 35 (41.7\%) & $22(35 \%)$ & \\
\hline Age of the patient [years]: & & & & NS $(0.9 \%)$ \\
\hline Under 65 & $191(76.1 \%)$ & $121(76.5 \%)$ & $68(74.7 \%)$ & \\
\hline Over 65 & $60(23.9 \%)$ & 37 (23.5\%) & $23(25.3 \%)$ & \\
\hline Age at onset [years]: & & & & NS $(0.6 \%)$ \\
\hline$<18$ & $20(5.6 \%)$ & $6(6.9 \%)$ & $6(9.5 \%)$ & \\
\hline $18-64$ & 307 (87.4\%) & $77(89.5 \%)$ & $53(84 \%)$ & \\
\hline$\geq 65$ & $24(6.8 \%)$ & $3(3.4 \%)$ & $4(6.5 \%)$ & \\
\hline Type of diabetes: & & & & NS $(0.9 \%)$ \\
\hline 1 & $66(18 \%)$ & $16(18.6 \%)$ & $12(19 \%)$ & \\
\hline 2 & $285(82 \%)$ & $70(81.4 \%)$ & $51(81 \%)$ & \\
\hline $\mathrm{HbA}_{1 \mathrm{c}}(\%):$ & & & & $<0.05$ \\
\hline$<7$ & 41 (11.6\%) & 10 (11.6\%) & $0(0 \%)$ & \\
\hline$\geq 7$ & $310(88.4 \%)$ & $76(88.4 \%)$ & $63(100 \%)$ & \\
\hline Duration of diabetes [years]: & & & & $<0.05$ \\
\hline$\leq 7$ & $133(37.9 \%)$ & $28(32.5 \%)$ & $12(19 \%)$ & \\
\hline$>7$ & $218(62.1 \%)$ & $58(67.5 \%)$ & $51(81 \%)$ & \\
\hline Diabetes medicine: & & & & $<0.05$ \\
\hline OAD alone & $36(10.2 \%)$ & $13(15.1 \%)$ & $1(1.5 \%)$ & \\
\hline Insulin alone & $108(30.7 \%)$ & $34(39.5 \%)$ & $28(44.4 \%)$ & \\
\hline Insulin + OAD & $206(58.6 \%)$ & $39(45.3 \%)$ & $34(54.1 \%)$ & \\
\hline BMI: & & & & NS $(0.7 \%)$ \\
\hline Normal & $59(16.8 \%)$ & $12(13.9 \%)$ & $9(14.2 \%)$ & \\
\hline Overweight & $88(25 \%)$ & $19(22 \%)$ & $13(20.6 \%)$ & \\
\hline Obese & $204(58.2 \%)$ & $55(64 \%)$ & $41(65 \%)$ & \\
\hline Hypertension: & & & & NS $(0.4 \%)$ \\
\hline Present & $214(60.9 \%)$ & $50(58.1 \%)$ & $43(68.2 \%)$ & \\
\hline Absent & $137(39.1 \%)$ & $36(41.9 \%)$ & $20(31.8 \%)$ & \\
\hline Smoking status: & & & & $<0.05$ \\
\hline Non-smoking & 252 (72\%) & $61(71 \%)$ & 37 (60\%) & \\
\hline Ex-smoker & $29(8.2 \%)$ & $10(11 \%)$ & $13(20 \%)$ & \\
\hline Current smoker & 70 (19.8\%) & $15(18 \%)$ & $13(20 \%)$ & \\
\hline Cholesterol [mg/dl]: & & & & NS $(0.7 \%)$ \\
\hline$\geq 200$ & $164(46.7 \%)$ & $37(43 \%)$ & $31(49.2 \%)$ & \\
\hline$<200$ & $187(53.3 \%)$ & $49(57 \%)$ & $32(51.8 \%)$ & \\
\hline Triglycerides [mg/dl]: & & & & NS $(0.9 \%)$ \\
\hline$\geq 150$ & $188(53.5 \%)$ & $46(53.4 \%)$ & $34(54.1 \%)$ & \\
\hline$<150$ & $163(46.5 \%)$ & $40(46.6 \%)$ & $29(45.9 \%)$ & \\
\hline Low-density lipoprotein [mg/dl]: & & & & NS $(0.1 \%)$ \\
\hline$\geq 100$ & $213(60.6 \%)$ & $45(52.3 \%)$ & $32(51.8 \%)$ & \\
\hline$<100$ & $138(39.4 \%)$ & $41(47.7 \%)$ & $31(49.2 \%)$ & \\
\hline High-density lipoprotein [mg/dl]: & & & & NS $(0.7 \%)$ \\
\hline Male $\geq 40$, female $\geq 50$ & $152(43.3 \%)$ & $36(41.8 \%)$ & $30(47.6 \%)$ & \\
\hline Male $<40$, female $<50$ & 199 (56.7\%) & $50(58.2 \%)$ & $33(52.4 \%)$ & \\
\hline
\end{tabular}


A

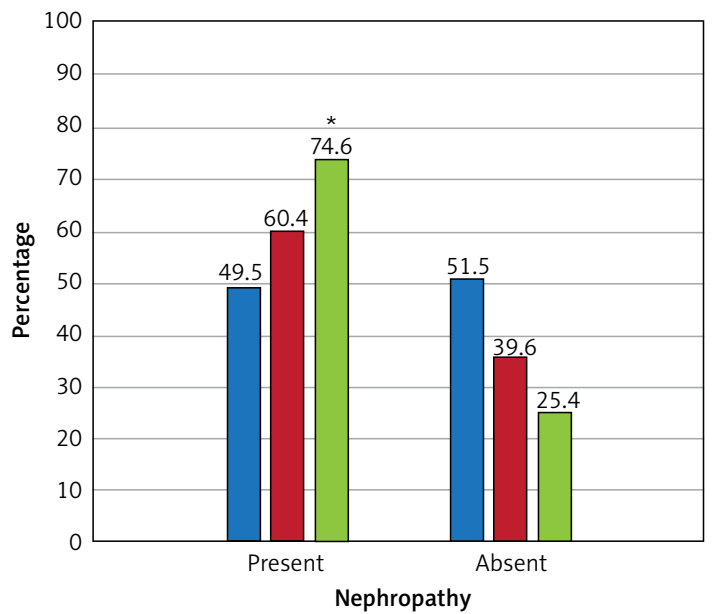

C

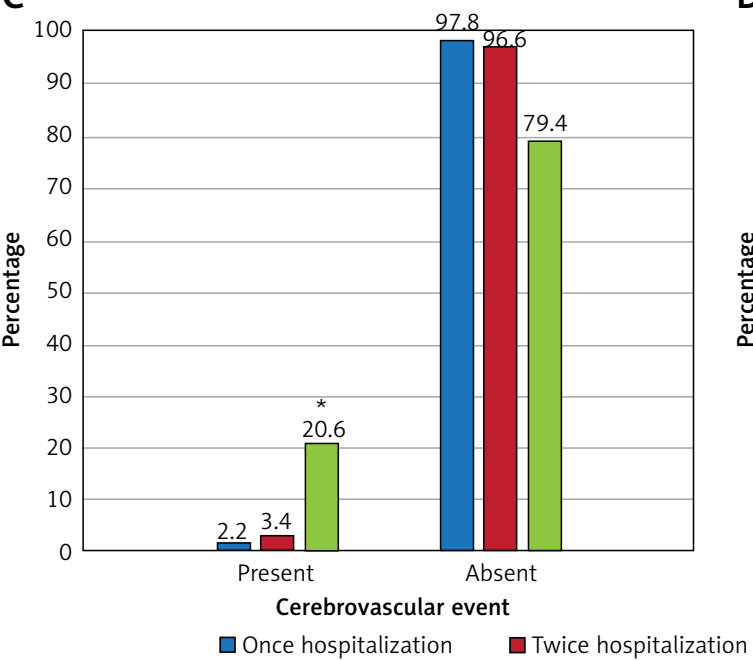

B

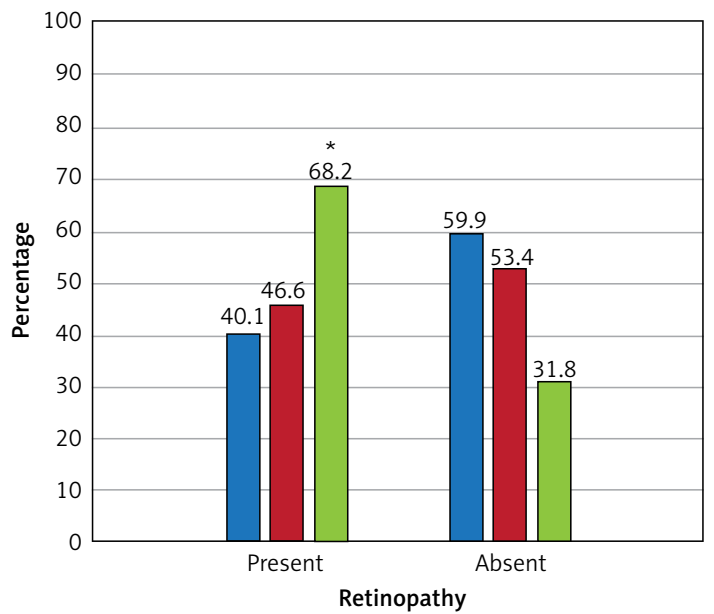

D

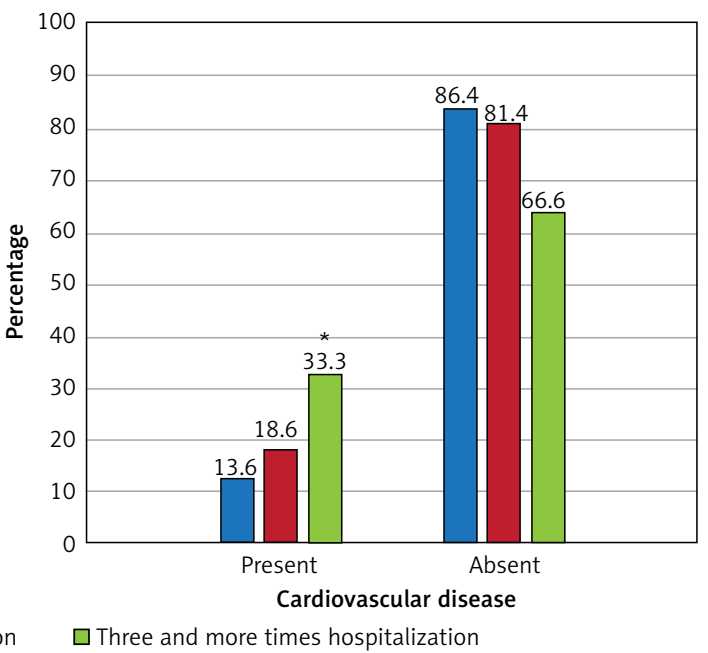

Figure 3. Relationship between number of hospitalizations and diabetic complications *Significant relationship.

drugs used had an effect. Although the effect of age, gender and body mass index was similar, unlike in our study, it was observed that there was a decrease in the number of hospitalizations in the non-smoking group compared to the smoker group.

Charron-Prochownik et al. [16] and Kovacs et al. [17] showed that high $\mathrm{HbA}_{1 \mathrm{c}}$ levels were a risk factor for hospitalization in similar studies conducted by younger age groups of patients in similar studies which included younger patients. In 2003, Jiang et al. [18] conducted a large scale study which included 648,000 people in the states of California, Missouri, New York, Tennessee, and Virginia in America. In this study, the relationship between diabetes-related multiple hospitalization data and hospital costs was examined. As a result of the study, it was found that $30 \%$ of the diabetic patients were hospitalized twice or more times and these patients' treatments accounted for at least $50 \%$ of hospital costs. In our study, it was found that the rate of those who were hospitalized twice was $17.2 \%$, while the rate of those who were hospitalized three or more times was $12.6 \%$. In our study, the rate of the patients hospitalized two or more times was in total $29.8 \%$, and this rate was similar to the rate reported by Jiang et al. [18]. While there was no significant relationship between gender, age and hospitalization rates in our study, Jiang et al. [18] noted that the hospitalization rate increased with age. Similar to our study, no significant association between gender and hospitalization was found. Differently, duration of diabetes, diabetic drug use, BMI, hypertension and smoking status were assessed in our study. While patients using insulin and oral anti-diabetic combinations, and non-smoking patients were found to have fewer hospitalizations, there was no significant difference in terms of duration of diabetes, $\mathrm{BMI}$ and hypertension.

The common result of the studies was that $\mathrm{HbA}_{1 \mathrm{c}}$ elevated hospitalization duration in both 
Table II. Statistical analysis between the number of hospitalizations and complications

\begin{tabular}{|c|c|c|c|c|}
\hline \multirow[t]{2}{*}{ Parameter } & \multicolumn{3}{|c|}{ Number of hospitalizations } & \multirow[t]{2}{*}{$P$-value } \\
\hline & 1 & 2 & $\geq 3$ & \\
\hline Nephropathy: & & & & $<0.05$ \\
\hline Present & $174(49.5 \%)$ & $52(60.4 \%)$ & $47(74.6 \%)$ & \\
\hline Absent & $177(51.5 \%)$ & $34(39.6 \%)$ & $16(25.4 \%)$ & \\
\hline Neuropathy: & & & & NS $(0.6 \%)$ \\
\hline Present & $82(23.3 \%)$ & $20(23.2 \%)$ & $18(28.5 \%)$ & \\
\hline Absent & $269(76.7 \%)$ & $66(76.8 \%)$ & $45(71.5 \%)$ & \\
\hline Retinopathy: & & & & $<0.001$ \\
\hline Present & $141(40.1 \%)$ & $40(46.6 \%)$ & $43(68.2 \%)$ & \\
\hline Absent & $210(59.9 \%)$ & $46(53.4 \%)$ & $20(31.8 \%)$ & \\
\hline Cerebrovascular event: & & & & $<0.001$ \\
\hline Present & $8(2.2 \%)$ & $3(3.4 \%)$ & $13(20.6 \%)$ & \\
\hline Absent & $343(97.8 \%)$ & $83(96.6 \%)$ & $50(79.4 \%)$ & \\
\hline Cardiovascular disease: & & & & $<0.001$ \\
\hline Present & $48(13.6 \%)$ & $16(18.6 \%)$ & $21(33.3 \%)$ & \\
\hline Absent & $303(86.4 \%)$ & $70(81.4 \%)$ & $42(66.6 \%)$ & \\
\hline Amputation: & & & & NS $(0.2 \%)$ \\
\hline Present & $9(2.5 \%)$ & $3(3.4 \%)$ & $4(6.3 \%)$ & \\
\hline Absent & $342(97.5 \%)$ & $83(96.6 \%)$ & $59(93.7 \%)$ & \\
\hline
\end{tabular}

type 1 and type 2 diabetics, resulting in an increase in cost per patient $[12,14,19,20]$. Shetty et al. [19] conducted a study to investigate diabetes-related costs by taking the target $\mathrm{HbA}_{1 \mathrm{c}}$ value of $7 \%$ for 1 year in type 2 diabetics, and it was found that the costs of diabetes with high levels of $\mathrm{HbA}_{1 \mathrm{c}}$ were about $36 \%$ higher than those of low $\mathrm{HbA}_{1 c}$ diabetics. In a similar study conducted by Oglesby et al. [20] in 2006, it was found that costs of diabetic patients with good glycemic control were between $16 \%$ and $20 \%$.

Besides studies showing negative effects of glycosylated hemoglobin levels on hospitalization rates, in some studies it was found that low $\mathrm{HbA}_{1 \mathrm{c}}$ was not always reflected positively in hospitalization rates. Especially when strict glycemic control was performed, complications related to diabetes and duration of hospitalization related to diabetes were found to increase. In type 2 diabetic patients with intensive treatment, it was found that having $\mathrm{HbA}_{1 \mathrm{c}}$ below $7 \%$ brought with it some cardiovascular problems [21]. In the study conducted by Ray et al. [22], it was noted that cardiovascular problems were reduced in type $2 \mathrm{DM}$ patients with strict glycemic control, but this condition did not seem to be valid for overall mortality and stroke. In our study, when the relationship between complications and the number of hospitalizations was examined, it was found that there was a significant relationship between nephropathy, retinopa- thy, cardiovascular disease, cerebrovascular event presence and number of hospitalizations. There was no significant relationship between neuropathy, amputation and the number hospitalizations.

Our study has strengths as well as limitations. Its strengths are the large design consisting of patients from both sexes representing a wide range of ages. In addition, our study is also important in that it shows that there is a significant relation between bad glycemic control, diabetes duration, smoking, diabetic complications and hospitalization in diabetic patients. Although there are very few studies in Turkey, the importance of our study increases because it is one of the rare studies in which wide participation of hospitalized patients was ensured. On the other hand, limitations are patients' subjective verbal responses to questions about smoking and smoking cessation. As these are not objective, data such as plasma concentration measurement and verbal responses have the possibility to be erroneous. In addition, it is known that the hospitalization indications of the diabetic patients are of interest for many clinics, and such patients are hospitalized in various services for treatment. For this reason, including only the patients who were hospitalized in the endocrinology service was an important limitation in our study.

In our study, it was found that there was a significant relationship between the number of diabetes-related hospitalization and poor glycemic 
control. Worse glycemic control, significantly longer duration of diabetes, and significantly higher rates of treatment of insulin alone were found in patients with three or more hospitalizations compared to patients with one or two hospitalizations. It was also found that the number of non-smokers in this group was significantly lower and the cessation rate was significantly higher. No significant relationship was found between the number of hospitalizations and other parameters. When the relationship between complications and number of hospitalizations was examined, it was found that there was a significant relationship between the presence of nephropathy, retinopathy, cerebrovascular and cardiovascular events and the number of hospitalizations. However, the same relationship was not observed in the presence of neuropathy and amputation. As a result, our study showed that glycemic control and diabetic complications were determinant for the control of diabetes-related hospitalizations, and good control of diabetes reduced the number of hospitalizations due to diabetes in Turkey. Since there are no cost data in this context, it is also anticipated that it will have a decreasing effect on the cost per patient.

\section{Conflict of interest}

The authors declare no conflict of interect.

\section{References}

1. Satman I, İmamoğlu Ş, Yılmaz C, Akalın S. ve Diyabetes Mellitus Çalışma ve Eğitim Grubu. TEMD Diyabetes Mellitus ve Komplikasyonlarının Tanı, Tedavi ve İzlem Kılavuzu, 5. Baskı. Bayt Matbaacılık, Ankara, 2011.

2. Hilton DJ, O'Rourke PK, Welborn TA, et al. Diabetes detection in Australian general practise: a comparison of diagnostic criteria. Med J Aust 2002; 176: 104-7.

3. Da Rocha Fernandes J, Ogurtsova K, Linnenkamp U, et al. IDF Diabetes Atlas estimates of 2014 global health expenditures on diabetes. Diabetes Res Clin Pract 2016; 117: 48-54.

4. The TURDEP Group. Population-based study of diabetes and risk characteristics in Turkey. Diabetes Care 2002; 25: 1551-6.

5. Satman I; the TURDEP Group. Population-Based Study of Diabetes and Risk Characteristics in Turkey. 32. Türkiye Endokrinoloji ve Metabolizma Hastalıkları Kongresi özet kitabı, Antalya, 2010: 24-9.

6. Zhaolan L, Chaowei F, Weibing W, et al. Prevalence of chronic complications of type 2 diabetes mellitus in outpatients - a cross-sectional hospital based survey in urban China. Health Qual Life Outcomes 2010; 8: 62.

7. Rhee SY, Chon S, Kwon MK, et al. Prevalence of chronic complications in Korean patients with type 2 diabetes mellitus based on the Korean National Diabetes Program. Diabetes Metab J 2011; 35: 504-12.

8. Menzin J, Langley-Hawthor C, Friedman M, et al. Potential short-term economic benefits of improved glycemic control: a managed care perspective. Diabetes Care 2001; 24: 51-5.
9. American Diabetes Association Professional Practice Committee. American Diabetes Association clinical practice recommendations. Diabetes Care 2013; 36 (Suppl 1): 1-110.

10. International Expert Committee. International Expert Committee report on the role of the A1c assay in the diagnosis of diabetes. Diabetes Care 2009; 32: 1327-34.

11. American Diabetes Association. Standards of medical care in diabetes 2015. Diabetes Care 2015; 38: 8-67.

12. Menzin J, Korn JR, Cohen J, et al. Relationship between glycemic control and diabetes-related hospital costs in patients with type 1 or type 2 diabetes mellitus. J Manag Care Pharm 2010; 16: 264-75.

13. Gilmer TP, O'Connor PJ, Rush WA, et al. Predictors of health care costs in adults with diabetes. Diabetes Care 2005; 28: 59-64.

14. Moss SE, Klein R, Klein BE. Risk factors for hospitalization in people with diabetes. Arch Intern Med 1999; 159: 2053-7.

15. Gilmer TP, O'Connor PJ, Rush WA, et al. Predictors of health care costs in adults with diabetes. Diabetes Care 2005; 28: 59-64.

16. Charron-Prochownik D, Kovacs M, Obrosky DS, et al. Biomedical and psychosocial predictors of early rehospitalization among children with insulin-dependent diabetes mellitus: a longitudinal study. Diabet Med 1994; 11: 372-7.

17. Kovacs M, Charron-Prochownik D, Obrosky DS. A longitudinal study of biomedical and psychosocial predictors of multiple hospitalizations among young people with insulin-dependent diabetes mellitus. Diabet Med 1995; 12: 142-8.

18. Jiang HJ, Stryer D, Friedman B, et al. Multiple hospitalizations for patients with diabetes. Diabetes Care 2003; 26: 1421-6.

19. Shetty S, Secnik K, Oglesby AK. Relationship of glycemic control to total diabetes-related costs for managed care health plan members with type 2 diabetes. J Manag Care Pharm 2005; 11: 559-64.

20. Oglesby AK, Secnik K, Barron J, et al. The association between diabetes-related medical costs and glycemic control: a retrospective analysis. Cost Eff Resour Alloc 2006; 4: 1

21. Montori VM, Fernandez-Balsells M. Glycemic control in type 2 diabetes: time for an evidence-based about-face. Ann Intern Med 2009; 150: 803-8.

22. Ray KK, Seshasai SR, Wijesuriya S, et al. Effect of intensive control of glucose on cardiovascular outcomes and death in patients with diabetes mellitus: a meta-analysis of randomised controlled trials. Lancet 2009; 373: 1765-72. 